\title{
Structural and magnetic characterization of zircon-type PrCrO4 oxide
}

DOI:

10.1016/S0925-8388(01)00978-1

\section{Document Version}

Final published version

Link to publication record in Manchester Research Explorer

\section{Citation for published version (APA):}

Jimenez-Melero, E., Isasi, J., \& Saez-Puche, R. (2001). Structural and magnetic characterization of zircon-type PrCrO4 oxide. Journal of Alloys and Compounds, 323-324, 115-118. https://doi.org/10.1016/S09258388(01)00978-1

\section{Published in:}

Journal of Alloys and Compounds

\section{Citing this paper}

Please note that where the full-text provided on Manchester Research Explorer is the Author Accepted Manuscript or Proof version this may differ from the final Published version. If citing, it is advised that you check and use the publisher's definitive version.

\section{General rights}

Copyright and moral rights for the publications made accessible in the Research Explorer are retained by the authors and/or other copyright owners and it is a condition of accessing publications that users recognise and abide by the legal requirements associated with these rights.

\section{Takedown policy}

If you believe that this document breaches copyright please refer to the University of Manchester's Takedown Procedures [http://man.ac.uk/04Y6Bo] or contact uml.scholarlycommunications@manchester.ac.uk providing relevant details, so we can investigate your claim.

\section{OPEN ACCESS}




\title{
Structural and magnetic characterization of zircon-type $\mathrm{PrCrO}_{4}$ oxide
}

\author{
E. Jiménez, J. Isasi, R. Sáez-Puche* \\ Dpto. Química Inorgánica I, Facultad de Ciencias Químicas, Universidad Complutense, 28040 Madrid, Spain
}

\begin{abstract}
$\mathrm{PrCrO}_{4}$ has been synthesized as a single phase using oxidizing conditions, with a strong control on temperature and time. The zircon-type structure that this compound adopts has been refined from X-ray powder diffraction by the Rietveld method, showing tetragonal symmetry with space group $I 4{ }_{1} / a m d$, lattice parameters $a=7.341(7) \AA, c=6.427(1) \AA$ and $Z=4$. Magnetic susceptibility measurements in the temperature range of $1.9-300 \mathrm{~K}$ reveal the presence of incipient ferromagnetic interactions in the $\mathrm{Cr}^{5+}$ sublattice $^{3}$ below $12 \mathrm{~K}$. When the temperature decreases, the superexchange $\mathrm{Pr}^{3+}-\mathrm{O}-\mathrm{Cr}^{5+}-\mathrm{O}-\mathrm{Pr}^{3+}$ antiferromagnetic interactions become predominant, giving rise to a net maximum at lower temperatures. The estimated Néel temperature is field-dependent, taking the value of $9 \mathrm{~K}$ when the magnetic field strength is $50 \mathrm{Oe}$. The $M$ vs. $H$ plots, at 2 and $8 \mathrm{~K}$, indicate the existence of a metamagnetic transition, having obtained a critical field as low as 399 and 149 Oe respectively at the temperatures mentioned above. (C) 2001 Elsevier Science B.V. All rights reserved.
\end{abstract}

Keywords: Magnetically ordered materials; Chemical synthesis; X-ray diffraction; Exchange and superexchange; Magnetic measurements

\section{Introduction}

The majority of the $\mathrm{RXO}_{4}$ compounds, with $X=\mathrm{P}, \mathrm{V}$ and As, adopts the zircon-type structure, showing tetragonal symmetry, space group $14_{1}$ /amd [1]. However, the compounds containing the heavier lanthanide trivalent ions crystallise in the monoclinic monazite form, space group $P 2_{1} / n$ [2]. The limiting zone between this two structural types is characterised by the presence of some compounds that show dimorphism [3-5].

The greater part of the $\mathrm{RCrO}_{4}$ oxides crystallise with the zircon structure [6]. This structural type can be described as built up by chains of edge-sharing distorted $\left(\mathrm{RO}_{8}\right)$ bisdisphenoids running parallel to the $a$-axis connected by $\mathrm{CrO}_{4}$ tetrahedra, sharing edges along the $c$-axis, as can be seen in Fig. 1. The first member of this family of compounds, $\mathrm{LaCrO}_{4}$, presents the monazite structure [7], while the next member of this series, $\mathrm{PrCrO}_{4}$, shows dimorphism. However, both structural types are always present simultaneously in the latter, and neither of them has been isolated in a pure form up to now. That is the reason why its magnetic properties have not been studied so far.

Besides, the studies carried out in the $\mathrm{RCrO}_{4}$ system up

*Corresponding author. Tel.: +34-91-394-4353; fax: +34-91-3944352.

E-mail address: rsp92@eucmax.sim.ucm.es (R. Sáez-Puche).

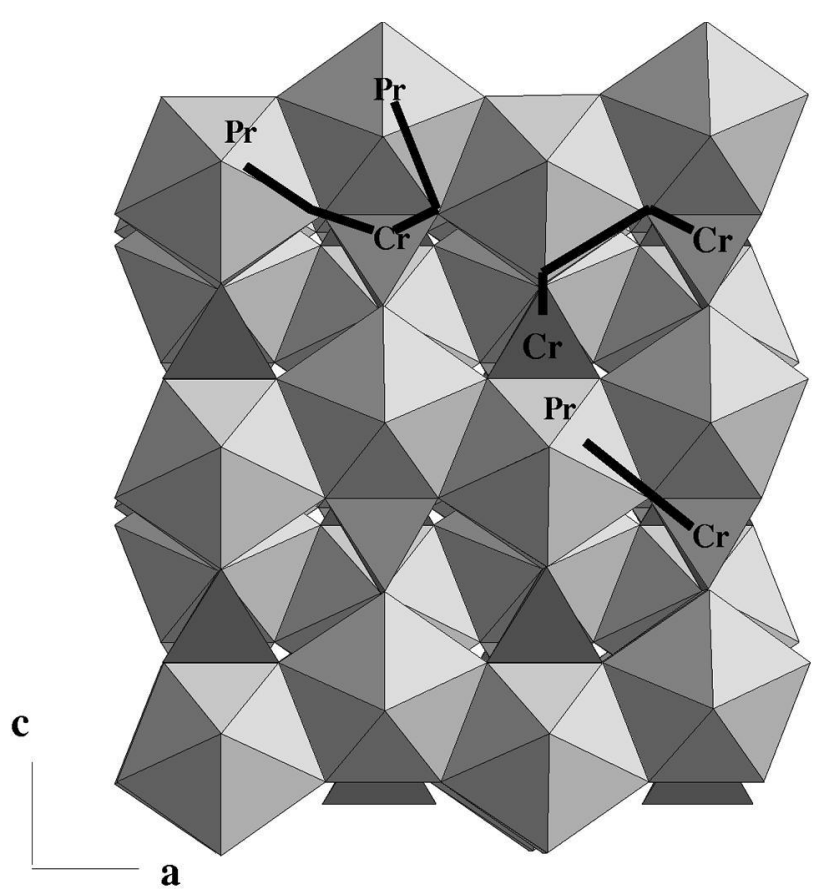

Fig. 1. Perspective view of the zircon-type structure showing the chains of edge-sharing $\left(\mathrm{RO}_{8}\right)$ bisdisphenoids polyhedra along the a axis connected by $\left(\mathrm{CrO}_{4}\right)$ tetrahedra. Bold lines are the pathways through which the magnetic interactions take place. 
to now, reflect the difficulty in preparing pure samples. This fact can be attributed to the instability of the $\mathrm{Cr}^{5+}$ in air at the temperatures that are necessary when preparing the different materials [8]. Magnetization and heat capacity measurements reveal that most of these oxides, namely from $\mathrm{GdCrO}_{4}$ to $\mathrm{YbCrO}_{4}$, show a ferromagnetic behaviour with Curie temperatures below $25 \mathrm{~K}$ [9]. However, the present magnetic susceptibility data obtained at low magnetic fields, indicate the evidence of an antiferromagnetic ordering. The reported ferromagnetic ordering could be ascribed to a field-induced effect.

In this work, we report the particular conditions used in the successful synthesis of the tetragonal $\mathrm{PrCrO}_{4}$ oxide as pure phase, coupled with a detailed description of its magnetic behaviour based on the structural characteristics.

\section{Experimental}

The zircon phase of the $\mathrm{PrCrO}_{4}$ was synthesized as pure sample by heating stoichiometric amounts of $\operatorname{Pr}\left(\mathrm{NO}_{3}\right)_{3}$. $6 \mathrm{H}_{2} \mathrm{O}$ and $\mathrm{Cr}\left(\mathrm{NO}_{3}\right)_{3} \cdot 9 \mathrm{H}_{2} \mathrm{O}$. The thermal scheme consisted of the following stages: $30 \mathrm{~min}$ at $433 \mathrm{~K}, 30 \mathrm{~min}$ at $473 \mathrm{~K}$, $60 \mathrm{~min}$ at $853 \mathrm{~K}$, followed by a quenching down to room temperature. These processes required the use of an oxygen flow that enables to stabilise $\mathrm{Pr}^{3+}$ and $\mathrm{Cr}^{5+}$ simultaneously. The reaction takes place according to:

$\mathrm{Pr}\left(\mathrm{NO}_{3}\right)_{3} \cdot 6 \mathrm{H}_{2} \mathrm{O}+\mathrm{Cr}\left(\mathrm{NO}_{3}\right)_{3} \cdot 9 \mathrm{H}_{2} \mathrm{O}=\mathrm{PrCrO}_{4}+6 \mathrm{NO}_{2}$ $+15 \mathrm{H}_{2} \mathrm{O}+\mathrm{O}_{2}$

The product obtained is green-coloured, and the X-ray diffraction pattern shows the existence of the tetragonal form as single phase.

The synthesis of this material corresponds with the indicated reaction, implying a kinetic mechanism that strongly depends on two variables: temperature and time. At low temperature, the monazite is the stable form. It transforms to the zircon phase when increasing both the heating time and/or the synthesis temperature. The oxygen quenching allows us to isolate the zircon phase from the mixture of monazite-zircon dimorphic $\mathrm{PrCrO}_{4}$, which has always been obtained in all the previous unsuccessful experiments. Attempts to isolate the monazite form as pure sample have been unsuccessful up to now. We have only obtained mixtures containing 50\% monazite. Moreover, experiments carried out in high oxygen pressure have not yielded pure samples.

Powder X-ray diffraction patterns were registered at a rate of $0.1^{\circ}(2 \theta) \mathrm{min}^{-1}$ using a Philips X'Pert MPD, Ni filtered $\mathrm{Cu} \mathrm{K} \alpha$ radiation. A step scan of $0.04^{\circ}(2 \theta)$ between 10 and $120^{\circ}$ and a counting time of $15 \mathrm{~s}$ for each step was employed. Rietveld full-profile refinement was done with FULLPROF program [10].

Magnetic susceptibility and magnetization measurements were performed in a Quantum Design XL-SQUID magnetometer, at different magnetic fields in the temperature range of $1.9-300 \mathrm{~K}$. The susceptibilities were corrected for ionic diamagnetism using the values of $-20 \times$ $10^{-6}$ emu. $\mathrm{mol}^{-1}$ for $\mathrm{Pr}^{3+},-12 \times 10^{-6} \mathrm{emu}^{-\mathrm{mol}^{-1}}$ for $\mathrm{O}^{2-}$

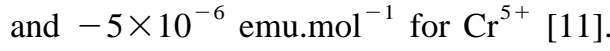

\section{Results and discussion}

\subsection{Structural characterization}

X-ray diffraction data for the $\mathrm{PrCrO}_{4}$ were analyzed by means of the Rietveld method (Program Fullprof), using the reflections proposed by Jiménez et al. [12] for $\mathrm{NdCrO}_{4}$. The final results of this refinement, including crystallographic parameters, the $R$-factors and main bond length distances, are presented in Table 1. As can be observed, the atoms occupy the following positions: praseodymium in $4 a(0,3 / 4,1 / 8)$, chromium in $4 b(0,1 / 4,3 / 8)$ and oxygen in $16 h(0, y, z)$. The Pr ions are centred in their respective distorted bisdisphenoids with an octa-coordination, presenting four long distances and four short dis-

Table 1

Structural parameters obtained from the Rietveld refinement for $\mathrm{PrCrO}_{4}{ }^{\mathrm{a}}$

\begin{tabular}{|c|c|c|c|}
\hline Space group & & I4 $/$ /amd & \\
\hline$a(\AA)$ & & $7.341(7)$ & \\
\hline$c(\AA)$ & & $6.427(1)$ & \\
\hline$Z$ & & 4 & \\
\hline$V\left(\AA^{3}\right)$ & & $346.3(5)$ & \\
\hline$R_{\mathrm{p}}$ & & 11.8 & \\
\hline$R_{\mathrm{wp}}$ & & 15.4 & \\
\hline$R_{\mathrm{b}}$ & & 10.6 & \\
\hline$\chi^{2}$ & & 5.14 & \\
\hline Atomic coordinates & & Experimental bond lengths $(\AA)$ & \\
\hline $\operatorname{Pr}$ & $4 a(0,3 / 4,1 / 8)$ & $\mathrm{Pr}-\mathrm{O}$ & $2.436(5) \times 4$ \\
\hline $\mathrm{Cr}$ & $4 b(0,1 / 4,3 / 8)$ & $\mathrm{Pr}-\mathrm{O}$ & $2.585(4) \times 4$ \\
\hline $\mathrm{O}$ & $16 h(0, y, z) y=0.429(1), z=0.221(4)$ & $\mathrm{Cr}-\mathrm{O}$ & $1.643(5) \times 4$ \\
\hline
\end{tabular}




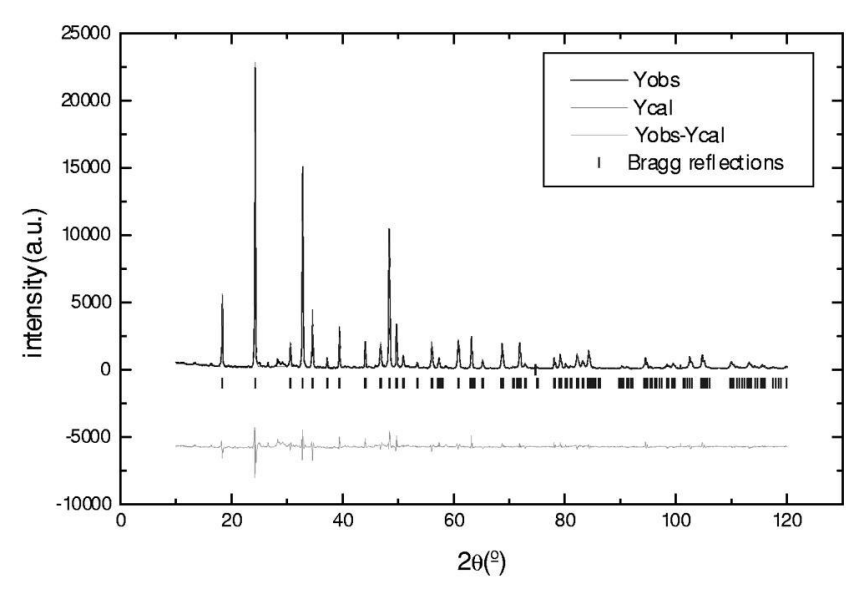

Fig. 2. X-ray diffraction pattern for $\mathrm{PrCrO}_{4}$ at room temperature.

tances; while the coordination of $\mathrm{Cr}$ is tetrahedral. The $\mathrm{Cr}-\mathrm{O}$ distances are remarkably shorter than the ones obtained for the remaining $\mathrm{RCrO}_{4}$ oxides, previously synthesized in our laboratories. The observed, calculated and difference X-ray profiles of powder diffraction for the $\mathrm{PrCrO}_{4}$ oxide are shown in Fig. 2.

\subsection{Magnetic measurements}

The temperature dependence of magnetic susceptibility for $\mathrm{PrCrO}_{4}$ at $100 \mathrm{Oe}$ is presented in Fig. 3. The experimental data obey a Curie-Weiss behaviour in the temperature range $12-300 \mathrm{~K}$. The Curie constant, $\mathrm{C}=1.92$ emu $\mathrm{K} \mathrm{mol}^{-1}$, which yields a magnetic moment of 3.92 $\mu_{B}$, agrees with the expected value taking into account the $\mathrm{Pr}^{3+}$ and $\mathrm{Cr}^{5+}$ paramagnetic contributions [13]. At $12 \mathrm{~K}$ the susceptibility shows a small sudden increase, which can be ascribed to the presence of incipient ferromagnetic interactions in the $\mathrm{Cr}^{5+}$ sublattice. Such interactions have been reported for the remaining isostructural zircon-type



Fig. 3. Temperature dependence of the molar magnetic susceptibility at $100 \mathrm{Oe}$ for $\mathrm{PrCrO}_{4}$. The inset is the $\chi T$ vs. $T$ plot.
$\mathrm{RCrO}_{4}$ compounds, where $R=\mathrm{Gd}-\mathrm{Tm}$ [9]. When the temperature decreases, the superexchange $\mathrm{Pr}^{3+}-\mathrm{O}-\mathrm{Cr}^{5+}$ and/or $\mathrm{Pr}^{3+}-\mathrm{O}-\mathrm{O}-\mathrm{Pr}^{3+}$ antiferromagnetic interactions become operative, giving rise to a net maximum at $8.8 \mathrm{~K}$. This maximum can be ascribed to the Néel temperature. The operativity of this antiferromagnetic interactions are confirmed by the decrease observed in the $\chi T$ vs. $T$ plot (Fig. 3 inset), attaining a value as small as $0.2 \mathrm{emu} \mathrm{K}$ $\mathrm{mol}^{-1}$ at $2 \mathrm{~K}$.

Fig. 4 shows the variation of the magnetic susceptibility with the temperature at different magnetic fields for the $\mathrm{PrCrO}_{4}$ oxide. As can be observed, the susceptibility data are field-independent above $20 \mathrm{~K}$, as was expected for a paramagnetic material. However, the Néel temperature diminishes when increasing the applied magnetic field and the net maximun vanishes at 1000 Oe. Such behaviour can be ascribed to the existence of metamagnetic processes, as it has been found in different materials with a low $T_{\mathrm{N}}$ $[13,14]$.

The magnetization versus the applied magnetic field plot at different temperatures is shown in Fig. 5, and the derivative $\mathrm{d} M / \mathrm{d} H$ vs. $H$ is presented in Fig. 6 . The data obtained at 2 and $8 \mathrm{~K}$ follow an $S$-shape characteristic of metamagnetic transitions. In the low magnetic-field range $(0-147 \mathrm{Oe}$ at $2 \mathrm{~K}$ and $0-51 \mathrm{Oe}$ at $8 \mathrm{~K})$, the experimental results fit a straight line. The subsequent increase in the magnetic field induces a spin reorientation in the antiferromagnetic order of $\mathrm{Pr}^{3+}$ and $\mathrm{Cr}^{5+}$ sublattices. Such order is modified at a critical magnetic field of 399 and 149 Oe at 2 and $8 \mathrm{~K}$, respectively (values taken from Fig. 6). The derivative $\mathrm{d} M / \mathrm{d} H$ vs. $H$ permits to visualize better this metamagnetic transition, from the net maximum that is present in the plot. The magnetic moment extrapolated from the linear part of the $M$ vs. $H$ representation, above the metamagnetic transition, takes the small value of 0.01 B.M., which is induced by the applied magnetic field.

As can also be observed in Fig. 5, when the temperature increases the magnetization diminishes. At $15 \mathrm{~K}$, the data

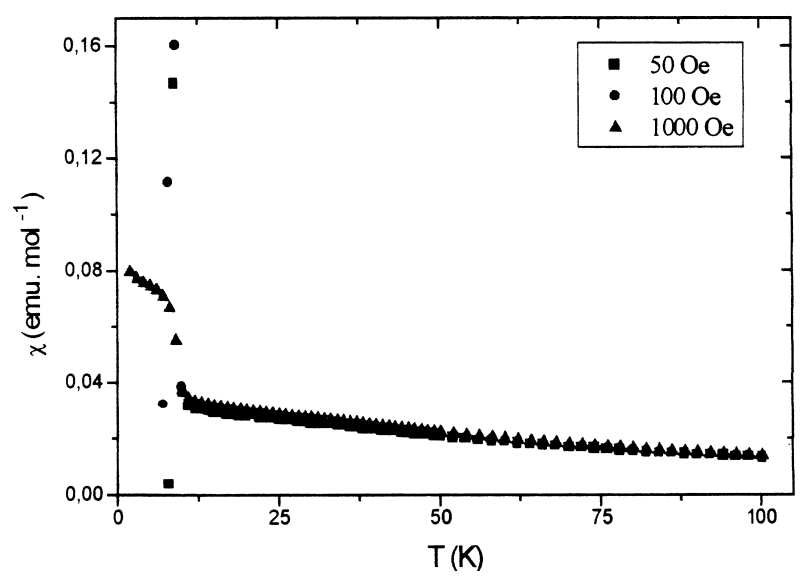

Fig. 4. Variation of the molar magnetic susceptibility with the temperature at different magnetic fields. 


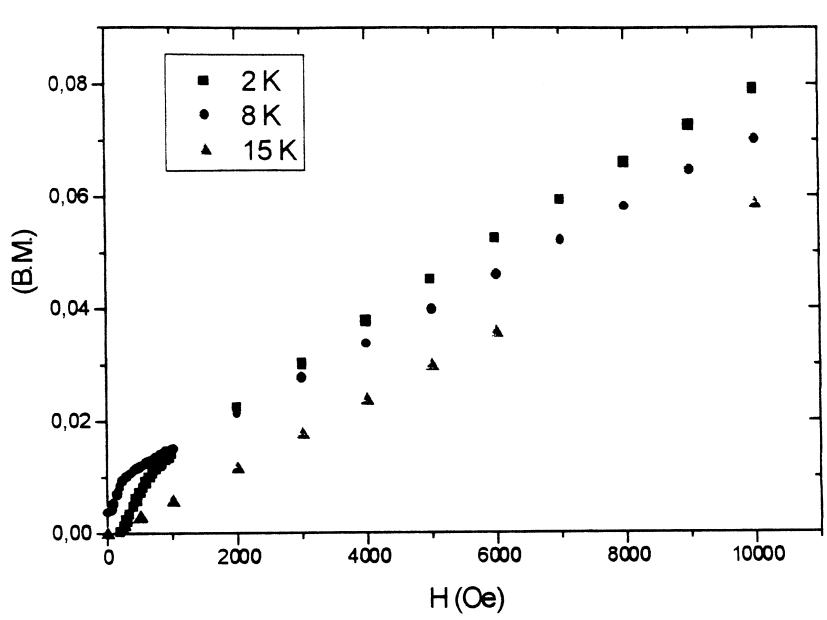

Fig. 5. $M$ vs. $H$ plot at different temperatures.

fit a straight line in the whole range of magnetic fields, in agreement with the paramagnetic behaviour of the sample at this temperature.

It is important to establish the possible pathways through which these interactions take place, taking into account both the structural description and the magnetic data of the $\mathrm{PrCrO}_{4}$ oxide. The superexchange mechanisms are quite complex, since several kinds of interactions must be inevitably considered. The pathways include the sequences $\mathrm{Cr}^{5+}-\mathrm{O}-\mathrm{O}-\mathrm{Cr}^{5+}, \mathrm{Cr}^{5+}-\mathrm{O}-\mathrm{Pr}^{3+}$ and $\mathrm{Pr}^{3+}-\mathrm{O}-$ $\mathrm{Cr}^{5+}-\mathrm{O}-\mathrm{Pr}^{3+}$, being oxygen ions involved in all cases, see Fig. 1. In the temperature range of $8.8-12 \mathrm{~K}$, the



Fig. 6. The derivative $\mathrm{d} M / \mathrm{d} H$ vs. $H$ plot at 2 and $8 \mathrm{~K}$.
$\mathrm{Cr}^{5+}-\mathrm{O}-\mathrm{O}-\mathrm{Cr}^{5+}$ ferromagnetic interactions predominate, because of the short $\mathrm{Cr}^{5+}-\mathrm{O}$ distances (see Table 1). Such interactions are overcome by the $\mathrm{Cr}^{5+}-\mathrm{O}-\mathrm{Pr}^{3+}$ and/or $\mathrm{Pr}^{3+}-\mathrm{O}-\mathrm{Cr}^{5+}-\mathrm{O}-\mathrm{Pr}^{3+}$ antiferromagnetic ones at lower temperatures. This behaviour originates the mentioned net maximum in the susceptibility vs. temperature representation. When the applied magnetic field exceeds the critical field $\left(H_{\mathrm{cr}}\right)$, the antiferromagnetic interactions are perturbed, giving rise to a small ferromagnetic component, as can be observed from the obtained susceptibility and magnetization data.

Neutron diffraction experiments are now in progress in order to get a deeper insight into the low temperature magnetic behaviour of this oxide, and to solve its magnetic structure.

\section{Acknowledgements}

We thank CICYT for financial support, under the project MAT-97-0697-C02-01.

\section{References}

[1] K.A. Gschneidner, L. Eyring, in: Handbook of the Physics and Chemistry of Rare Earths, North-Holland, 1987, p. 91.

[2] H. Saji, T. Yakamada, M. Asanuda, J. Phys. Soc. Jpn. 28 (1970) 913.

[3] H. Schwarz, Z. Anorg. Allg. Chem. 323 (1963) 44.

[4] M.E. Escobar, E.J. Baran, Z. Anorg. Allg. Chem. 441 (1978) 272.

[5] E.J. Baran, An. Asoc. Quím. Argent. 66 (1978) 227.

[6] G. Buisson, F. Bertaut, J. Mareschal, C.R. Acad. Sci. Paris 259 (1964) 411

[7] J.D. Carter, H.U. Anderson, M.G. Shumsky, J. Mater. Sci. 31 (1996) 551.

[8] S.G. Manca, E.J. Baran, J. Phys. Chem. Solids 42 (1981) 923.

[9] H. Walter, H.G. Kahle, K. Mulder, H.C. Schopper, H. Schwarz, Int. J. Magn. 5 (1973) 129.

[10] J. Rodríguez-Carvajal, in Abst. of the Satellite Meeting on Powder Diffraction of XVth. Congress of the Int. Union of Crystallography, Toulouse, 1990, p. 127.

[11] L.N. Mulay, E. Boudreaux, in: Theory of Molecular Paramagnetism, Wiley, New York, 1976, p. 494.

[12] E. Jiménez, J. Isasi, R. Sáez-Puche, J. Alloys Comp. 312 (2000) 53.

[13] A.H. Morrish, The Physical Principles of Magnetism, R.E. Krieger Publish, Huntington, New York, 1980.

[14] A. Salinas, Doctoral Thesis, Universidad Complutense de Madrid, 1992. 